\title{
OPEN ACCESS \\ Prey size selection and bottom type influence multiple predator effects in a crab-bivalve system
}

\author{
Melisa C. Wong ${ }^{1,2, *}$, Charles H. Peterson ${ }^{1}$, Jenessa Kay ${ }^{1}$ \\ ${ }^{1}$ Institute of Marine Sciences, University of North Carolina at Chapel Hill, 3431 Arendell St., Morehead City, \\ North Carolina 28557, USA
}

${ }^{2}$ Present address: Fisheries and Oceans Canada, Bedford Institute of Oceanography, 1 Challenger Dr., Dartmouth, Nova Scotia B2Y 4A2, Canada

\begin{abstract}
Consumption by multiple conspecific or interspecific predators on shared prey is not always predicted when data from isolated predators are combined. Predator interactions can result in non-independent predator effects on prey, and may be influenced by prey size selection and bottom type. We examined stone crab Menippe mercenaria and blue crab Callinectes sapidus predation of hard clams Mercenaria mercenaria. Interactions between these predators may become common in mid-Atlantic estuaries as stone crab abundance increases with a poleward range shift driven by climate change. Crabs in isolation, in conspecific pairs and in the interspecific pair were offered clams in 5 size classes simultaneously (10-60 mm shell length [SL]) or 1 size class (10-20 mm SL). Trials were on sand and hard bottom. On sand, all predator pairs had independent effects on prey, regardless of the presence or absence of multiple prey sizes. On hard bottom, when multiple prey sizes were present, blue crab conspecific and the interspecific pairs consumed less than predicted from isolated crabs. Strong selection of small clams by blue crabs led to conspecific interactions that reduced foraging compared to isolated crabs. Because stone crabs consumed all clam sizes, behaviours other than prey size selection caused the non-independent effect on prey by the interspecific pair. When multiple prey sizes were absent on hard bottom, most predator pairs had independent effects on prey. Thus, an expected poleward range shift of stone crabs may not increase interactions with blue crabs when foraging on sand. However, on hard bottom, increased predator interactions could reduce overall predation risk for prey, especially when consuming multiple prey sizes. In a climate-changed midAtlantic estuary, stone crabs will consume a wide range of clam sizes, and the size refuge large clams usually have from blue crab predation will be lost.
\end{abstract}

KEY WORDS: Bottom type - Multiple predator effects · Predator interactions · Prey size selection · Poleward range shift · Callinectes sapidus · Menippe mercenaria · Mercenaria mercenaria

\section{INTRODUCTION}

Multiple predator species that consume similar prey resources are commonly observed in nature. The effects of multiple predator species on prey are often studied by determining if overall predation can be predicted by summing consumption by each predator in isolation (e.g. Soluk 1993, Sih et al. 1998, Vance-Chalcraft \& Soluk 2004). If the observed proportion of prey consumed does not differ from predicted values, the multiple predator effect on prey is independent. This results when interactions among predators, such as interference, exploitation and intraguild predation, are negligible, or predator activity does not change prey behaviours (Sih et al. 1998). Non-independent multiple predator effects on prey occur when the proportion of prey consumed differs from predicted values, either reducing or enhancing predation risk for prey. Risk reduction occurs when the observed proportion of prey consumed is less than predicted, and results when predator interactions or prey behaviours reduce foraging success (Mansour \& Lipcius 1991, Soluk 1993, Griffen \& Byers 2006). Risk-enhancement, where the observed proportion of prey consumed is greater than predicted, results when predator facilita- 
tion or prey behaviour enhances foraging success (Soluk 1993). Non-independent multiple predator effects can occur both when conspecific or interspecific predators forage together (Vance-Chalcraft \& Soluk 2004). Effects of multiple predator species on prey are only evident when the magnitude of difference between observed and predicted values of consumption differs between the conspecific and interspecific cases, indicating effects are not dependent on predator density (Vance-Chalcraft \& Soluk 2004).

While most multiple predator studies have examined predation on a single prey type, predator selection among different prey types could influence multiple predator effects. Predator selection occurs when the relative frequency of a certain prey type differs in the predator's diet compared to the environment (Chesson 1983). Selection of prey can result from a predator maximizing intake of profitable prey (i.e. energy content divided by handling time per prey; Stephens \& Krebs 1986). The presence of multiple conspecific or interspecific predators may change a predator's prey selection compared to when it forages alone. Isolated predators similar in morphology and energy requirements would likely select similar prey types. However, if these predators interact when foraging together, both predators may be less selective. If one predator is dominant, the subordinate predator may change selection patterns to reduce interactions with the dominant predator. If predators do not directly interact, selection patterns may change if prey availability is reduced and predators switch to more abundant prey (Murdoch 1969). Changes in prey selection could influence multiple predator effects on prey by altering predator interactions and the total amount of prey consumed. Despite the ecological implications, few studies to our knowledge have examined how prey selection influences effects of multiple predators on prey (but see Wilbur \& Fauth 1990, Smallegange et al. 2008).

Multiple predator effects on prey could also be influenced by bottom type. Coarse-grained sediments can reduce penetrability by predators, resulting in lower encounter rates with prey and lower consumption rates compared to predation on finer sediments (Seitz et al. 2001). Consumption rates of crabs preying on infaunal clams are consistently higher on mud than on sand (Lipcius \& Hines 1986, Seitz et al. 2001), and on sand than on sediments with larger particle size or shell debris (Arnold 1984, Sponaugle \& Lawton 1990). Changes to predator behaviours induced by bottom type, such as longer search times on coarse versus fine sediments, could influence predator interactions and, consequently, the multiple predator effect on prey.

We studied multiple predator-multiple prey interactions using a system from North Carolina, USA, consisting of blue crabs Callinectes sapidus and Florida stone crabs Menippe mercenaria preying on different sizes of hard clams Mercenaria mercenaria. Blue crabs range throughout the US east coast, and are important predators of macrobenthic fauna (Virnstein 1977, Hines et al. 1990). Blue crabs readily consume bivalves, and are particularly ferocious predators of hard clams (Arnold 1984, Peterson 1990). Stone crabs range from Florida to North Carolina (Williams 1965). In North Carolina, stone crabs have historically been low in abundance. However, the range limit of stone crabs could be shifted poleward if seawater temperatures continue warming with global climate change. Poleward range shifts have been observed for other marine organisms (Southward et al. 1995, Walther et al. 2002, Helmuth et al. 2006). Stone crab abundance in North Carolina may increase with a poleward range shift because species abundance is usually highest in the range centre, while it declines towards the range edges (Sagarin et al. 2006). Recent observations and interviews with North Carolina fish harvesters have confirmed an increase in stone crab abundance in recent years (D. Eggleston pers. comm., C. H. Peterson pers. obs.), and this increase is expected to continue with seawater warming. Shoreline stabilization structures (i.e. stone sills, bulkheads) built to reduce shoreline erosion caused by rising sea level and storms (NRC 2007) will facilitate population growth of stone crabs because stone crabs prefer hard structures for shelter and burrow stabilization (Lindberg \& Marshall 1984). While few studies have examined Florida stone crab foraging, studies of the Gulf of Mexico stone crab Menippe adina suggest that the Florida stone crab will readily prey on bivalves (Aronhime \& Brown 2009). It is likely that stone crabs and blue crabs will compete for similar prey resources such as hard clams. The objectives of the present study were to determine (1) if predation by blue crabs and stone crabs on various sizes of hard clams results in independent or non-independent multiple predator effects on prey, (2) if multiple predator effects differ when predators are offered multiple prey sizes simultaneously compared to a single prey size, (3) if prey size selection by predators foraging in isolation, in conspecific pairs and in the interspecific pair differs, (4) if multiple predator effects differ when predators forage on sand compared to hard bottom, and (5) how predator behaviours and prey characteristics contribute to the observed predation results.

\section{MATERIALS AND METHODS}

Experimental materials and setup. Predation by blue crabs Callinectes sapidus and stone crabs Menippe mercenaria on hard clams Mercenaria mercenaria was investigated using 2 laboratory experiments. The first experiment incorporated multiple prey sizes and was conducted July to August 2006. The sec- 
ond experiment used 1 prey size and was conducted June to July 2007. In both experiments, 8 wooden fiberglass tanks $(0.8 \times 0.8 \times 0.5 \mathrm{~m}$, length $\times$ width $\times$ height) with flow-through seawater ( 0.5 to $\left.11 \mathrm{~min}^{-1}\right)$ were used. A semi-circular shelter for crabs constructed from PVC pipe cut in half (radius $=0.15 \mathrm{~m}$ ) was placed in 2 opposing tank corners. Natural light was supplied by large south-facing windows. Water temperature was similar to ambient temperature, and ranged from 27.5 to $29.9^{\circ} \mathrm{C}$ during the multiple preysize experiment, and 26.3 to $29.0^{\circ} \mathrm{C}$ during the single prey-size experiment.

Crabs were collected using baited pots in Bogue Sound, North Carolina. Before the experiments began, each species of crab was held in different tanks large enough to minimize intraspecific aggression (holding tanks measured $4.5 \times 1.55 \times 0.8 \mathrm{~m}$, length $\times$ width $\times$ height). Concrete cinder blocks were placed in each holding tank to provide shelter for the crabs. Crabs were fed frozen fish daily, and food was withheld 2 to $3 \mathrm{~d}$ prior to each trial to standardize hunger levels. Only male crabs in the intermolt stage that had both chelae and all walking legs were used. Crab carapace width (CW) was measured as the distance between the tips of the 2 most distal marginal teeth. Blue crabs ranged from 97 to $140 \mathrm{~mm} \mathrm{CW}$ and stone crabs from 85 to $130 \mathrm{~mm} \mathrm{CW}$. Crabs of similar sizes were paired in multiple predator environments. Although blue crabs are less robust and have smaller claws than similarly sized stone crabs, pairings were based on size to remove the size effect on predator encounters (Jachowski 1974, Sinclair 1977) while examining how inherent species differences influence predator interactions. Effort was made to use new crabs for each trial; however, difficulties in obtaining the required numbers necessitated reuse of a small number of stone crabs. Prior to reuse, stone crabs were held in holding tanks for $\sim 4$ to $5 \mathrm{~d}$ under the feeding regime detailed above.

Hard clams were obtained from Mill Point Aquaculture, Sea Level, North Carolina, and held in raceways with flow-through seawater prior to experimental trials. Clam shell length (SL) was measured as the longest anterior to posterior shell dimension. For the multiple prey-size experiment, clams were divided into 5 size classes: 10-20, 21-30, 31-40, 41-50 and 51-60 mm SL. Each size class was painted a different colour at the umbo (Painters acrylic paint, Elmer's Products) for identification of size during behavioural observations. The single prey-size experiment used clams 10-20 mm SL.

Experimental design. Factors in both experiments were predator environment (5 levels: blue crab in isolation, blue crab conspecific pair, stone crab in isolation, stone crab conspecific pair, and interspecific pair) and bottom type (2 levels: sand and hard bottom). We included hard bottom to provide insight into multiple pre- dator effects on prey colonizing hard structures, such as the shoreline stabilization structures built to reduce shoreline erosion. Although hard clams are not epifaunal and are usually not found on hard bottom, we elected to use the same prey as for sand treatments to allow direct comparison of multiple predator effects. The hard bottom treatment also allowed quantification of consumption rate and prey selection over time, which was difficult to quantify on sand. In the multiple prey-size experiment, 10 clams of each size class were offered simultaneously to the predator(s) for an initial total of 50 clams per tank. In the single prey-size experiment, 100 clams 10-20 mm SL were initially offered. Densities were chosen so that total clam biomass was not limiting at the end of the trials. Before the trials began, clams were planted in a uniform distribution in the sediment or placed directly on the tank bottom, using a metal frame subdivided into a $10 \times 10$ grid with monofilament line. In the multiple prey-size experiment, clam size was randomly assigned to half of the grid squares. Clams were not replaced when consumed. Six (multiple prey-size experiment) or 8 (single prey-size experiment) replicates of each treatment combination were randomly allocated to the 8 tanks over $8 \mathrm{~d}$ (multiple prey-size experiment) or $10 \mathrm{~d}$ (single prey-size experiment). The final replicate number for each treatment combination varied from 4 to 8 because some crabs died unexpectedly (remaining crabs were feeding readily). Two additional control tanks had 50 clams and no predators to account for natural clam mortality. In the multiple prey-size experiment, trials began between 14:00 and 18:00 $\mathrm{h}$ and ran for $24 \mathrm{~h}$. In the single prey-size experiment, trials began at 24:00 and ran for $6 \mathrm{~h}$. The single prey-size experiment used shorter trials to minimize depletion of prey abundance. Trials during the single prey-size experiment were conducted during peak activity times of both crab species (Brown \& Haight 1992, Clark et al. 1999b).

Collection of predation data. Tanks with sand were sampled by hand, using fingers to plow the sediments thoroughly at the end of the trials to recover live clams and shell fragments. For hard-bottom treatments, the numbers of clams consumed were recorded after 1,2 , $4,6,12,18$ and $24 \mathrm{~h}$ (multiple prey-size experiment) or 2, 4 and $6 \mathrm{~h}$ (single prey-size experiment) from the start of the trial. For paired predator treatments, only total consumption was recorded because consumption by individual predators could not be determined. Biomass consumed for each size class of clams was calculated by multiplying the number consumed in each size class by mean biomass for that size class. The total proportion of clam biomass consumed was calculated as total biomass consumed divided by total biomass available at the start of the trial. On hard bottom, the proportion of clam biomass consumed per hour within each time interval was also calculated. 
The proportional numbers of clams in each size class consumed during the multiple prey-size experiment were calculated as the number in a size class eaten divided by the number of clams available in that size class at the start of the trial. These data were used to calculate Chesson's selection index:

$$
\alpha_{i}=\frac{\ln \left(\left(n_{i 0}-r_{i}\right) / n_{i 0}\right)}{\sum_{j=1}^{m} \ln \left(\left(n_{j 0}-r_{j}\right) / n_{j 0}\right)}, i=1, \ldots, m
$$

where both $i$ and $j$ denote prey size class, $\alpha$ is the predator's deviation from random sampling of prey size class, $r$ is the number of prey in the predator's diet, $n_{0}$ is the number of prey in the environment at the beginning of the trial and $m$ is the total number of prey size classes available for consumption by the predator (Chesson 1983). We calculated this measure by combining clam size classes into 3 groups: small (size classes 1 and 2), medium (size class 3) and large (size classes 4 and 5). $\alpha_{i}=1$ when only prey size $i$ was consumed, $\alpha_{i}=0$ when no prey size $i$ was consumed, and $\alpha_{i}=0.333$ when there was no size selection. Grouping size classes provided enough data for calculations within each time interval on hard bottom, and for indices on sand, and allowed for more powerful statistical tests. The index is not influenced by prey density (Chesson 1983). Indices were calculated using data cumulative over time at the end of the trials, and using data within each time interval on hard bottom.

In the multiple prey-size experiment, prey profitability was measured to determine mechanisms underlying observed selection. Tissues from 20 clams in each size class were dried for $48 \mathrm{~h}$ at $60^{\circ} \mathrm{C}$ and weighed. Dried tissue was multiplied by $25.4 \mathrm{~kJ} \mathrm{~g}^{-1}$ dry tissue weight to calculate energy content (Hibbert 1977). Prey profitability per clam size class was calculated as mean energy content per prey divided by mean handling time per prey (Charnov 1976, Rovero et al. 2000). Inclusion of prey sizes in the predator diets were determined by ranking prey profitability and using Eq. (2.11) of Stephens \& Krebs (1986) with observed encounter rates with prey. Profitability was calculated only on hard bottom because observations of handling time per prey and encounter rates on sand were too few for use.

Collection of behavioural data. In the multiple preysize experiment, predator and prey behaviours were quantified using $1 \mathrm{~h}$ observation periods conducted in the morning, afternoon and night throughout each $24 \mathrm{~h}$ trial. Total observation time was $\sim 3$ to $7 \mathrm{~h}$ for each replicate of each predator environment on each bottom type. A blind constructed from black plastic and suspended from the ceiling was used to avoid observer effects on predators. Night observations were conducted using red light. Foraging behaviours (searching for and handling prey) and non-foraging behaviours (walking, inactivity when buried or unburied and watching the other crab while buried or unburied), were quantified. A focal animal was indicated by a white paint dot on the top of the carapace and observed in treatments with multiple predators. Only blue crabs were observed in the interspecific pair to avoid confounding behavioural data from each predator species. Additional interspecific replicates for observations of only stone crabs were not possible because of limited stone crab availability. The proportions of time spent searching and handling were calculated as the total duration of the behaviour divided by the total observation time (Wong \& Barbeau 2005). The proportion of time spent foraging was calculated as the total time spent foraging divided by the total observation time. Encounter rates between predators and their outcomes were calculated as the number of physical contacts with the other predator divided by observation time. Encounter rates between predators and prey on hard bottom and their outcomes were calculated as the number of physical contacts with prey divided by the predator search time (Wong \& Barbeau 2005). Detailed descriptions of the behaviours are given in the 'Results'.

Results from the multiple prey-size experiment suggested that encounters between predators influenced multiple predator effects. Thus, in the single prey-size experiment, encounter rates between predators on hard bottom were quantified in additional trials using $1 \mathrm{~h}$ observation periods between 21:00 and 24:00 h. Other behaviours in the single prey-size experiment were not quantified.

Statistical analyses. The proportions of clam biomass consumed were analysed using a 2-way ANOVA, with predator environment ( 5 levels) and bottom type (2 levels) as fixed factors. The proportions of biomass consumed per hour within each time interval on hard bottom were analysed using a split-plot ANOVA, with predator environment as the fixed factor, time ( 7 and 3 levels for the multiple prey-size and single prey-size experiments, respectively) as the split-plot factor and tank ( $\sim 8$ replicate tanks) as the random plot factor.

To test for multiple predator effects (both conspecific and interspecific pairs) on prey, we compared observed proportions of biomass consumed to predicted values generated using the multiplicative risk model (Wilbur \& Fauth 1990, Soluk 1993, Sih et al. 1998):

$$
C_{a b}=P_{a}+P_{b}-\left(P_{a} P_{b}\right)
$$

where $C_{a b}$ is the predicted proportion of biomass consumed by predator $a$ and predator $b$ when foraging together, $P_{a}$ is the observed proportion of biomass consumed by predator $a$ in isolation and $P_{b}$ is the observed proportion of biomass consumed by predator $b$ in isolation. The proportion of clam biomass was used so data from all clam size classes could be combined for meaningful examination of multiple predator effects. This 
model is derived from the addition theorem of probability (Soluk 1993). The $P_{a} P_{b}$ term accounts for biomass consumed by one predator that cannot be consumed by another predator. This means prey depletion is taken into account and the model is appropriate for our experimental design (Sih et al. 1998). To generate predicted values for each multiple predator combination (i.e. blue crab conspecific pair, stone crab conspecific pair, interspecific pair), replicate data from the appropriate isolated predator treatments were paired in all possible combinations for each different multiple predator environment. Each data pair was used in the multiplicative risk model to generate a series of predicted values. The mean and $\mathrm{SD}$ of these data were calculated for each multiple predator environment and represent the final predicted value. Predicted values were calculated from data at the end of each trial, and also from data at $6 \mathrm{~h}$ on hard bottom in the multiple prey-size experiment. The latter computation allowed comparison with data from the $6 \mathrm{~h}$ trials in the single prey-size experiment. We compared observed and predicted values using a 1-way ANOVA for each multiple predator environment and bottom type combination. If significant differences were apparent for both conspecific and interspecific pairs, the magnitudes of difference between the observed and predicted values were compared using a 1-way ANOVA to determine if results were dependent on predator density.

For the multiple prey-size experiment, we examined the proportional numbers of clams consumed in each size class using a multivariate ANOVA (MANOVA) with predator environment and bottom type as fixed factors. Pillai's trace was used to identify significant results (Scheiner 2001). To aid in the interpretation of significant results, we also conducted canonical correlation analyses (Scheiner 2001). To determine the treatment level of significant main factors leading to the result, we conducted separate MANOVAs for each pair of treatment levels (Hotelling's $T^{2}$, Scheiner 2001).

One-sample Hotelling's $\mathrm{T}^{2}$ tests were used to determine if selection indices cumulative over time differed from the expected value of no selection (i.e. 0.333) (Roa 1992, Wong et al. 2006). This test was used because selection indices for each size group were not independent of each other. Separate tests were conducted for each predator environment. Significant results were investigated by calculating $95 \%$ confidence intervals for each size group as:

$$
\overline{X_{i}} \pm\left[(1 / n) S_{i}^{2} \frac{(n-1) p}{n-p} F_{\alpha_{i} p, n-p}\right]^{1 / 2}
$$

where $\overline{X_{i}}$ is the mean selection index of size group $i, s_{i}^{2}$ is the sample variance for size group $i$, and $p$ is the number of size groups (Johnson \& Wichern 2002). A size group contributed to the significant result when the confidence interval did not include the expected value
(Roa 1992). Tests were conducted only on the small and medium size groups to avoid linear dependence. Single and paired blue crabs did not consume large clams, so selection of small clams by these predator environments were tested using a 1-sample $t$-test. A 2-way ANOVA examined the effect of predator environment and bottom type on the cumulative selection indices for small clams. On hard bottom, a split-plot ANOVA examined if selection for small clams changed over time.

Behavioural data collected during the multiple preysize experiment were analysed using 2-way ANOVAs with predator environment and bottom type as the fixed factors, and the proportions of time spent searching, handling or foraging, or encounter rates between predators as the dependent variable. Handling times per prey on hard bottom were analysed using a 2-way ANOVA with predator species and clam size class as the fixed factors. Few handling events on sand were observed and could not be analysed statistically.

For ANOVAs, multiple comparisons used a StudentNewman-Keul's (SNK) test. The assumption of homogeneity of variance was tested using Cochran's test. Violations were corrected using square root transformations. For MANOVAs, the assumption of equal covariance among groups was evaluated using the sign of the correlation between dependent variables at each level of the independent factors (Scheiner 2001).

\section{RESULTS}

\section{Proportions of biomass consumed}

In the multiple prey-size experiment, the proportions of biomass consumed were significantly higher on hard bottom than on sand (SNK test, p $<0.05$; Table 1, Fig. 1a). Predator environment had a significant effect on the proportions of biomass consumed after $24 \mathrm{~h}$ (Table 1, Fig. 1a). Blue crabs in isolation and blue crab conspecific pairs consumed the smallest proportion of biomass available, the interspecific pairs an intermediate amount and stone crabs in isolation and stone crab conspecific pairs the greatest (SNK test, $\mathrm{p}<0.05$ ). Analysis of the proportions of biomass consumed per hour on hard bottom indicated that the interaction between predator environment and time was significant (Table 1). Hourly consumption rate by blue crabs in isolation was significantly higher after the first hour than after other time intervals (SNK test, $\mathrm{p}<0.05$ ). Isolated and paired blue crabs as well as the interspecific pair tended to have higher consumption rates at the beginning of the trials than at the end (SNK test, p < 0.05). Isolated and paired stone crabs had higher consumption rates after 4, 6, 12 and $18 \mathrm{~h}$ than isolated and paired blue crabs. 
Table 1. Results of ANOVAs for proportions of clam biomass consumed in the multiple prey-size experiment and the single prey-size experiment. Data for the multiple prey-size experiment were square root transformed. Post hoc comparisons are ordered according to increasing magnitude of treatment means; those sharing a common underline do not differ significantly. df1: numerator df; df2: denominator df; P: predator environment; B: bottom type; $\mathrm{T}$ : time; BC: blue crab; SC: stone crab; $\mathrm{p}$-values in bold indicate significant results

\begin{tabular}{|c|c|c|c|c|c|c|}
\hline Analysis & $\begin{array}{l}\text { Source of } \\
\text { variation }\end{array}$ & $\begin{array}{c}\text { Effect } \\
\text { MS }\end{array}$ & $\begin{array}{c}\text { Error } \\
\text { MS }\end{array}$ & $F_{\mathrm{df1}, \mathrm{df} 2}$ & $\mathrm{p}$ & Post hoc comparisons \\
\hline $\begin{array}{l}\text { Multiple prey-size experiment } \\
\text { Effect of predator environment } \\
\text { and bottom type }\end{array}$ & $\begin{array}{c}\mathrm{P} \\
\mathrm{B} \\
\mathrm{P} \times \mathrm{B}\end{array}$ & $\begin{array}{l}0.119 \\
0.277 \\
0.014\end{array}$ & $\begin{array}{l}0.023 \\
0.023 \\
0.023\end{array}$ & $\begin{array}{l}5.20_{4,49} \\
12.1_{1,49} \\
0.63_{4,49}\end{array}$ & $\begin{array}{l}\mathbf{0 . 0 0 1} \\
\mathbf{0 . 0 0 1} \\
0.643\end{array}$ & $\begin{array}{llll}\mathrm{BC} \quad \mathrm{BC}+\mathrm{BC} & \mathrm{BC}+\mathrm{SC} \quad \mathrm{SC} & \mathrm{SC}+\mathrm{SC} \\
\text { Sand Hard } & & & \end{array}$ \\
\hline $\begin{array}{l}\text { Effect of predator environment } \\
\text { and time on hard bottom }\end{array}$ & $\begin{array}{c}\mathrm{P} \\
\mathrm{T} \\
\mathrm{P} \times \mathrm{T}\end{array}$ & $\begin{array}{l}0.012 \\
0.026 \\
0.009\end{array}$ & $\begin{array}{l}0.009 \\
0.005 \\
0.005\end{array}$ & $\begin{array}{l}1.23_{4,27} \\
4.89_{6,162} \\
1.75_{24,162}\end{array}$ & $\begin{array}{l}0.323 \\
0.0001 \\
\mathbf{0 . 0 2 3}\end{array}$ & 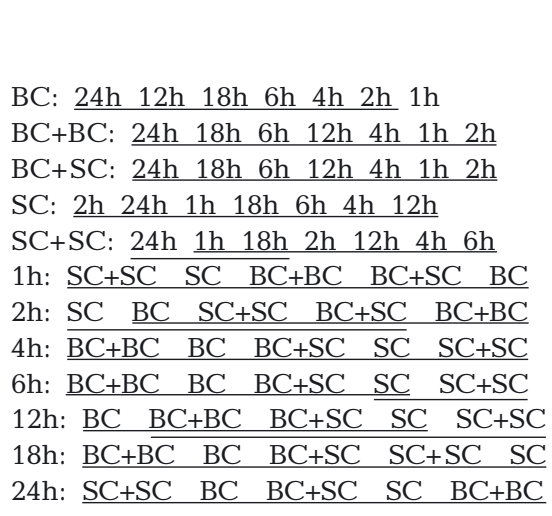 \\
\hline $\begin{array}{l}\text { Single prey-size experiment } \\
\text { Effect of predator environment } \\
\text { and bottom type }\end{array}$ & $\begin{array}{c}\mathrm{P} \\
\mathrm{B} \\
\mathrm{P} \times \mathrm{B}\end{array}$ & $\begin{array}{l}0.525 \\
0.970 \\
0.043\end{array}$ & $\begin{array}{l}0.044 \\
0.044 \\
0.044\end{array}$ & $\begin{array}{l}11.9_{4,65} \\
22.0_{1,65} \\
0.97_{4,65}\end{array}$ & $\begin{array}{c}<\mathbf{0 . 0 0 0 1} \\
<\mathbf{0 . 0 0 0 1} \\
0.430\end{array}$ & $\begin{array}{l}\mathrm{SC} \quad \mathrm{BC} \quad \mathrm{SC}+\mathrm{SC} \quad \mathrm{BC}+\mathrm{SC} \quad \mathrm{BC}+\mathrm{BC} \\
\text { Sand Hard }\end{array}$ \\
\hline $\begin{array}{l}\text { Effect of predator environment } \\
\text { and time on hard bottom }\end{array}$ & $\begin{array}{c}\mathrm{P} \\
\mathrm{T} \\
\mathrm{P} \times \mathrm{T}\end{array}$ & $\begin{array}{l}0.038 \\
0.043 \\
0.013\end{array}$ & $\begin{array}{l}0.004 \\
0.007 \\
0.007\end{array}$ & $\begin{array}{l}9.51_{4,34} \\
6.07_{2,61} \\
1.77_{7,61}\end{array}$ & $\begin{array}{c}<\mathbf{0 . 0 0 0 1} \\
\mathbf{0 . 0 0 4} \\
0.120\end{array}$ & $\begin{array}{llll}\underline{\mathrm{SC}} \quad \mathrm{BC} \quad \mathrm{BC}+\mathrm{SC} & \mathrm{SC}+\mathrm{SC} & \mathrm{BC}+\mathrm{BC} \\
\underline{6 \mathrm{~h}} 4 \underline{\mathrm{h}} 2 \mathrm{~h} & \end{array}$ \\
\hline
\end{tabular}

In the single prey-size experiment, the proportions of biomass consumed were significantly higher on hard bottom than on sand (SNK test, $\mathrm{p}<0.05$; Table 1, Fig. 1c). After $6 \mathrm{~h}$, stone crabs in isolation had consumed significantly less of the available biomass than that consumed by other predator environments (SNK test, $\mathrm{p}<0.05$; Table 1, Fig. 1c). Also, interspecific and conspecific pairs of crabs consumed more than isolated crabs, and conspecific pairs of blue crabs consumed the highest proportions of clam biomass (SNK test, p < 0.05). Analysis of the proportions of biomass consumed per hour on hard bottom indicated that consumption was significantly higher during the first $2 \mathrm{~h}$ interval than after 4 or $6 \mathrm{~h}$ of the trials (Table 1 ).

\section{Multiple predator effects}

When foraging on sand, conspecific and interspecific predator pairs had independent effects on prey in both experiments (Table 2, Fig. 1). When foraging on hard bottom, comparison of observed and predicted propor- tions of biomass consumed indicated that, in some cases, multiple predators had non-independent effects on prey (Table 2, Fig. 1). In the multiple prey-size experiment, observed consumption was significantly less than predicted for the blue crab conspecific pairs and the interspecific pairs after both 6 and $24 \mathrm{~h}$ on hard bottom (Fig. 1a,b). The departure of the observed value from the predicted value was significantly larger for the interspecific pair than for the blue crab conspecific pair after $24 \mathrm{~h}\left(F_{1,11}=11.7, \mathrm{p}=0.006\right)$, and marginally so after $6 \mathrm{~h}\left(F_{1,11}=3.36, \mathrm{p}=0.094\right)$. In the single prey-size experiment, observed consumption on hard bottom was significantly higher than predicted for the stone crab conspecific pairs, but did not differ for the blue crab conspecific or interspecific pairs (Fig. 1c).

\section{Proportional numbers of prey eaten and selection of prey}

In the multiple prey-size experiment, MANOVA indicated that the proportional numbers of clams con- 

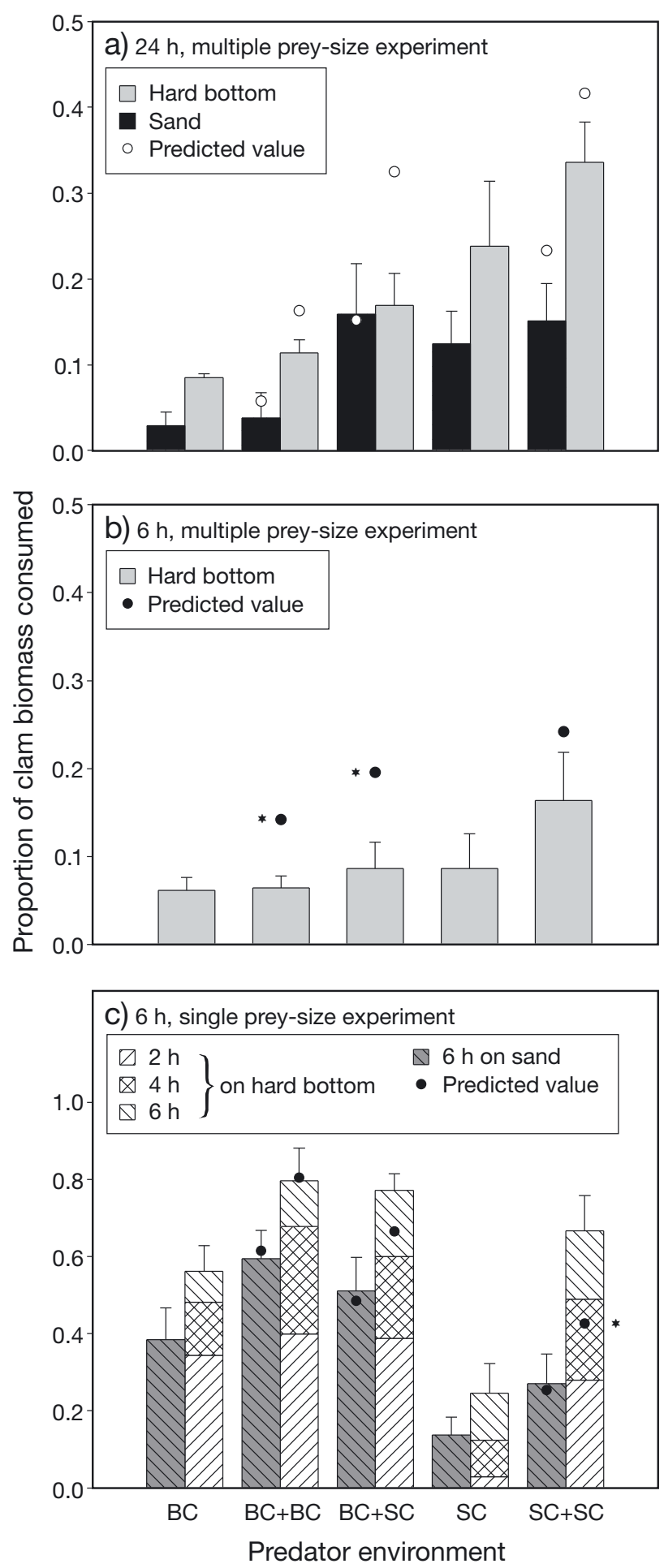

Fig. 1. Callinectes sapidus, Menippe mercenaria and Mercenaria mercenaria. Observed (bars) and predicted (circles) proportions of hard clam biomass consumed by predators after (a) $24 \mathrm{~h}$ and (b) $6 \mathrm{~h}$ in the multiple prey-size experiment, and (c) after $6 \mathrm{~h}$ in the single prey-size experiment. Predicted values were generated using the multiplicative risk model. BC: blue crab; $\mathrm{SC}$ : stone crab. ${ }^{*}$ Predicted value differs significantly from the observed value $(p<0.05)$. Error bars are +1 SE, $n=4$ to 8 sumed were significantly higher on hard bottom than on sand (square root transformed, $F_{5,44}=12.4, \mathrm{p}<$ 0.0001) (Fig. 2). Predator environment had a significant effect on the proportional numbers of prey in each size class consumed $\left(F_{20,188}=2.20, p=0.003\right)$ (Fig. 2$)$. Coefficients of the first standardized canonical variate indicated that size class 3 and 4 clams most influenced this result (0.964 and 0.558 , respectively). Blue crabs in isolation and in conspecific pairs consumed fewer size class 3 and 4 clams than stone crabs in isolation and in conspecific pairs, and the interspecific pairs (Hotelling's $\left.\mathrm{T}^{2}, \mathrm{p}<0.05\right)$.

When cumulative selection indices were examined on both bottom types in the multiple prey-size experiment, blue crabs in isolation and blue crab conspecific pairs strongly selected small (size classes 1 and 2 combined) over medium (size class 3) or large (size classes 4 and 5 combined) clams (Table S1 in Supplement 1, see www.int-res.com/articles/suppl/m409p143_supp. pdf, Fig. 3a). Isolated stone crabs on both bottom types consumed large clams less than the expected value of 0.333. On sand, the interspecific pair selected large clams less than expected. On hard bottom, the interspecific pairs selected small clams more than expected and medium and large clams less than expected. Stone crab conspecific pairs on sand did not preferentially select a certain clam size, but selected large clams less than expected on hard bottom.

Selection indices cumulative over time for small clams (size classes 1 and 2 combined) were not significantly affected by bottom type $\left(F_{1,46}=0.89, \mathrm{p}=0.349\right)$ (Fig. 3a). However, indices for small clams were significantly affected by predator environment $\left(F_{4,46}=10.3\right.$, $\mathrm{p}<0.0001$ ) (Fig. 3a). Indices were highest for blue crabs in isolation and in conspecific pairs, intermediate for interspecific pairs, and lowest for stone crabs in isolation and in conspecific pairs (SNK test, p < 0.05). Selection indices for small clams on hard bottom per time interval were significantly affected by time $\left(F_{6,61}\right.$ $=6.18, \mathrm{p}<0.0001$ ) (Fig. 3b-f). Generally, strong selection for small clams was observed within the first $6 \mathrm{~h}$ of the trials (SNK test, $\mathrm{p}<0.05$ ).

\section{Profitability of prey}

Clam profitability increased with clam size (Table 3). Handling time per prey on hard bottom was significantly influenced by predator species $\left(F_{1,85}=14.02, \mathrm{p}=\right.$ $0.0003)$ and clam size class $\left(F_{4,85}=7.06, \mathrm{p}<0.0001\right)$. Stone crabs had a longer handling time per prey than blue crabs, and handling time per prey increased with clam size (although it did not differ between size classes 1 and 2; SNK test, p < 0.05). Although few instances of handling time per prey on sand were 
Table 2. Results of 1-way ANOVAs that compare the observed proportions of biomass consumed by blue crabs and stone crabs with predicted values generated from the multiplicative risk model. Predicted values (mean \pm SD) are provided. df1: numerator df; df2: denominator df; BC: blue crab; SC: stone crab; O: observed value; P: predicted value; p-values in bold indicate significant results

\begin{tabular}{|c|c|c|c|c|c|c|c|c|}
\hline Experiment & $\begin{array}{c}\text { Predator } \\
\text { environment }\end{array}$ & $\begin{array}{l}\text { Bottom } \\
\text { type }\end{array}$ & $\begin{array}{l}\text { Effect } \\
\text { MS }\end{array}$ & $\begin{array}{l}\text { Error } \\
\text { MS }\end{array}$ & $F_{\mathrm{df} 1, \mathrm{df} 2}$ & $\mathrm{p}$ & $\begin{array}{l}\text { Post hoc } \\
\text { comparisons }\end{array}$ & $\begin{array}{l}\text { Predicted proportion } \\
\text { of biomass consumed }\end{array}$ \\
\hline \multirow[t]{6}{*}{ Multiple prey sizes, 24 h } & $\mathrm{BC}+\mathrm{BC}$ & Hard & 0.011 & 0.0004 & $25.0_{1,25}$ & $<0.0001$ & $\mathrm{O}<\mathrm{P}$ & $0.16 \pm 0.01$ \\
\hline & $\mathrm{BC}+\mathrm{BC}$ & Sand & 0.0012 & 0.003 & $0.47_{1,17}$ & 0.504 & & $0.06 \pm 0.05$ \\
\hline & $\mathrm{SC}+\mathrm{SC}$ & Hard & 0.030 & 0.034 & $0.88_{1,25}$ & 0.357 & & $0.42 \pm 0.20$ \\
\hline & $\mathrm{SC}+\mathrm{SC}$ & Sand & 0.031 & 0.0130 & $2.41_{1,25}$ & 0.133 & & $0.23 \pm 0.16$ \\
\hline & $\mathrm{BC}+\mathrm{SC}$ & Hard & 0.140 & 0.022 & $6.30_{1,27}$ & 0.018 & $\mathrm{O}<\mathrm{P}$ & $0.32 \pm 0.16$ \\
\hline & $\mathrm{BC}+\mathrm{SC}$ & Sand & 0.0002 & 0.012 & $0.02_{1,24}$ & 0.892 & & $0.15 \pm 0.10$ \\
\hline \multirow[t]{3}{*}{ Multiple prey sizes, $6 \mathrm{~h}$} & $\mathrm{BC}+\mathrm{BC}$ & Hard & 0.026 & 0.0009 & $28.1_{1,19}$ & $<0.0001$ & $\mathrm{O}<\mathrm{P}$ & $0.14 \pm 0.03$ \\
\hline & $\mathrm{SC}+\mathrm{SC}$ & Hard & 0.023 & 0.014 & $1.61_{1,14}$ & 0.226 & & $0.24 \pm 0.11$ \\
\hline & $\mathrm{BC}+\mathrm{SC}$ & Hard & 0.053 & 0.005 & $9.86_{1,16}$ & 0.006 & $\mathrm{O}<\mathrm{P}$ & $0.20 \pm 0.06$ \\
\hline \multirow[t]{6}{*}{ Single prey size, $6 \mathrm{~h}$} & $\mathrm{BC}+\mathrm{BC}$ & Hard & 0.0004 & 0.022 & $0.02_{1,34}$ & 0.892 & & $0.80 \pm 0.11$ \\
\hline & $\mathrm{BC}+\mathrm{BC}$ & Sand & 0.003 & 0.045 & $0.07_{1,42}$ & 0.800 & & $0.61 \pm 0.21$ \\
\hline & $\mathrm{SC}+\mathrm{SC}$ & Hard & 0.335 & 0.049 & $6.86_{1,27}$ & 0.014 & $\mathrm{O}>\mathrm{P}$ & $0.43 \pm 0.21$ \\
\hline & $\mathrm{SC}+\mathrm{SC}$ & Sand & 0.002 & 0.027 & $0.06_{1,27}$ & 0.806 & & $0.25 \pm 0.14$ \\
\hline & $\mathrm{BC}+\mathrm{SC}$ & Hard & 0.066 & 0.021 & $3.09_{1,27}$ & 0.090 & & $0.66 \pm 0.15$ \\
\hline & $\mathrm{BC}+\mathrm{SC}$ & Sand & 0.004 & 0.044 & $0.09_{1,27}$ & 0.763 & & $0.48 \pm 0.20$ \\
\hline
\end{tabular}

observed, comparison of values from preliminary trials with hard-bottom values indicate that handling time per prey did not differ between bottom types for either predator on any clam size. Energy content of clams increased significantly with size $\left(F_{4,95}=136.4, \mathrm{p}<\right.$ 0.0001 ; SNK test, $\mathrm{p}<0.05$ ), except between size classes 1 and 2 (SNK test, $p>0.05$ ). Ranking of prey profitability using encounter rates with prey on hard bottom (Fig. S1 in Supplement 1) showed that both crab species should consume all prey sizes when foraging on hard bottom. Few encounters with prey on sand were observed. Incorporating a lower encounter rate on sand than on hard bottom into profitability calculations would lower the left-hand side of the algorithm (Stephens \& Krebs 1986). This would not change which prey should be included in the diet of predators, especially because handling times per prey did not differ between bottom types.

\section{Foraging and encounter behaviours}

Both crab species searched for prey by probing the bottom with their walking legs. When crabs foraged on sand, time spent digging for buried clams was considered a component of search behaviour. Handling began with physical contact with a clam, and ended with consumption or rejection of the clam. Blue crabs opened smaller clams (size classes 1 and 2) by crushing or pulling apart the valves, while larger clams (size classes 3 to 5) were opened by chipping the shell margin. Stone crabs opened smaller clams (size classes 1 and 2) by crushing the entire clam, while larger clams (size classes 3 to 5) were opened by cracking across the umbo or by pulling the valves apart. Stone crabs often returned to discarded shell fragments to consume tissue left on them. Blue crabs foraging with stone crabs also consumed meat from shell fragments discarded by stone crabs.

Table 3. Characteristics of hard clams used in the multiple prey-size experiment. Units are $\mathrm{kJ} \mathrm{prey}^{-1}$ (energy content per prey), min prey $^{-1}$ (handling time per prey), and $\mathrm{kJ} \mathrm{min}^{-1}$ (profitability). Handling times per prey are from hard bottom. Blue crabs were not observed handling all sizes of clams, so an intermediate value was used (size class 4 ) or estimated from preliminary trials (size class 5). Clam size classes 1 to 5 were 10-20, 21-30, 31-40, 41-50 and 51-60 mm shell length, respectively. Means are presented \pm SE (n)

\begin{tabular}{|c|c|c|c|c|c|}
\hline \multirow[t]{2}{*}{ Clam size class } & \multirow{2}{*}{$\begin{array}{l}\text { Energy content } \\
\text { per clam }\end{array}$} & \multicolumn{2}{|c|}{ Blue crab } & \multicolumn{2}{|c|}{ Stone crab } \\
\hline & & Handling time per prey & Profitability & Handling time per prey & Profitability \\
\hline 1 & $1.1 \pm 0.07(20)$ & $2.80 \pm 0.49(14)$ & 0.39 & $2.36 \pm 1.93(2)$ & 0.47 \\
\hline 2 & $2.6 \pm 0.24(20)$ & $3.87 \pm 0.35(53)$ & 0.67 & $2.38 \pm 0.62(2)$ & 1.09 \\
\hline 3 & $6.4 \pm 0.23(20)$ & $12.46 \pm 10.45(2)$ & 0.51 & $5.23 \pm 0.85(9)$ & 1.22 \\
\hline 4 & $12.7 \pm 0.52(20)$ & 14.0 & 0.90 & $9.73 \pm 3.47(7)$ & 1.31 \\
\hline 5 & $20.7 \pm 1.41(20)$ & $16.72(1)$ & 1.24 & $13.68 \pm 4.08(4)$ & 1.51 \\
\hline
\end{tabular}




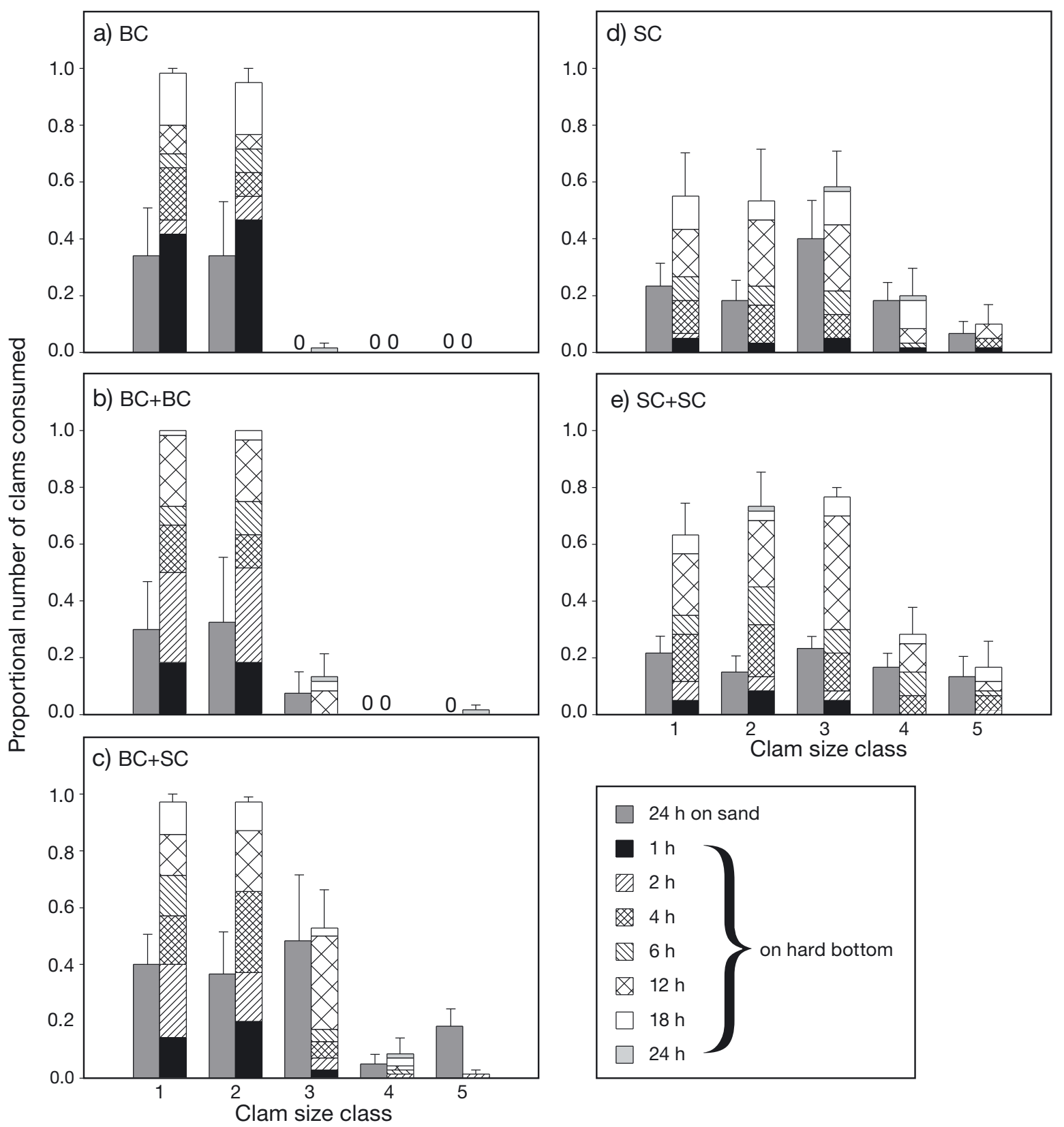

Fig. 2. Callinectes sapidus, Menippe mercenaria and Mercenaria mercenaria. Proportional numbers of clams consumed in each size class by predators in the multiple prey-size experiment. Clam size classes 1 to 5 were 10-20, 21-30, 31-40, 41-50 and 51-60 mm shell length (SL), respectively. BC: blue crab; SC: stone crab. Error bars are $+1 \mathrm{SE}, \mathrm{n}=4$ to 7

Encounters between predators had several outcomes: non-aggression, where predators physically touched but then moved apart; threatening behaviour, where predators raised their chelae while facing each other; fighting, where predators locked chelae or pinched the other $\mathrm{crab}_{\text {; }}$ and chasing, where one predator chased the other.

Non-foraging behaviour included walking or resting. Resting crabs either sat on top of both bottom types, or buried themselves in the sand. During resting, one of the paired crabs often positioned themselves in close proximity to and facing the other crab. This non-foraging behaviour was designated 'watching'.

In the multiple prey-size experiment, all foraging behaviours were significantly higher on hard bottom than on sand (SNK test, p < 0.05; Table S2 in Supplement 1, Fig. 4a). Foraging behaviours of crabs were not significantly affected by predator environment. However, the proportion of time spent foraging tended to be lowest for single blue crabs in sand compared to all other predator environments across both sediment types. It also tended 

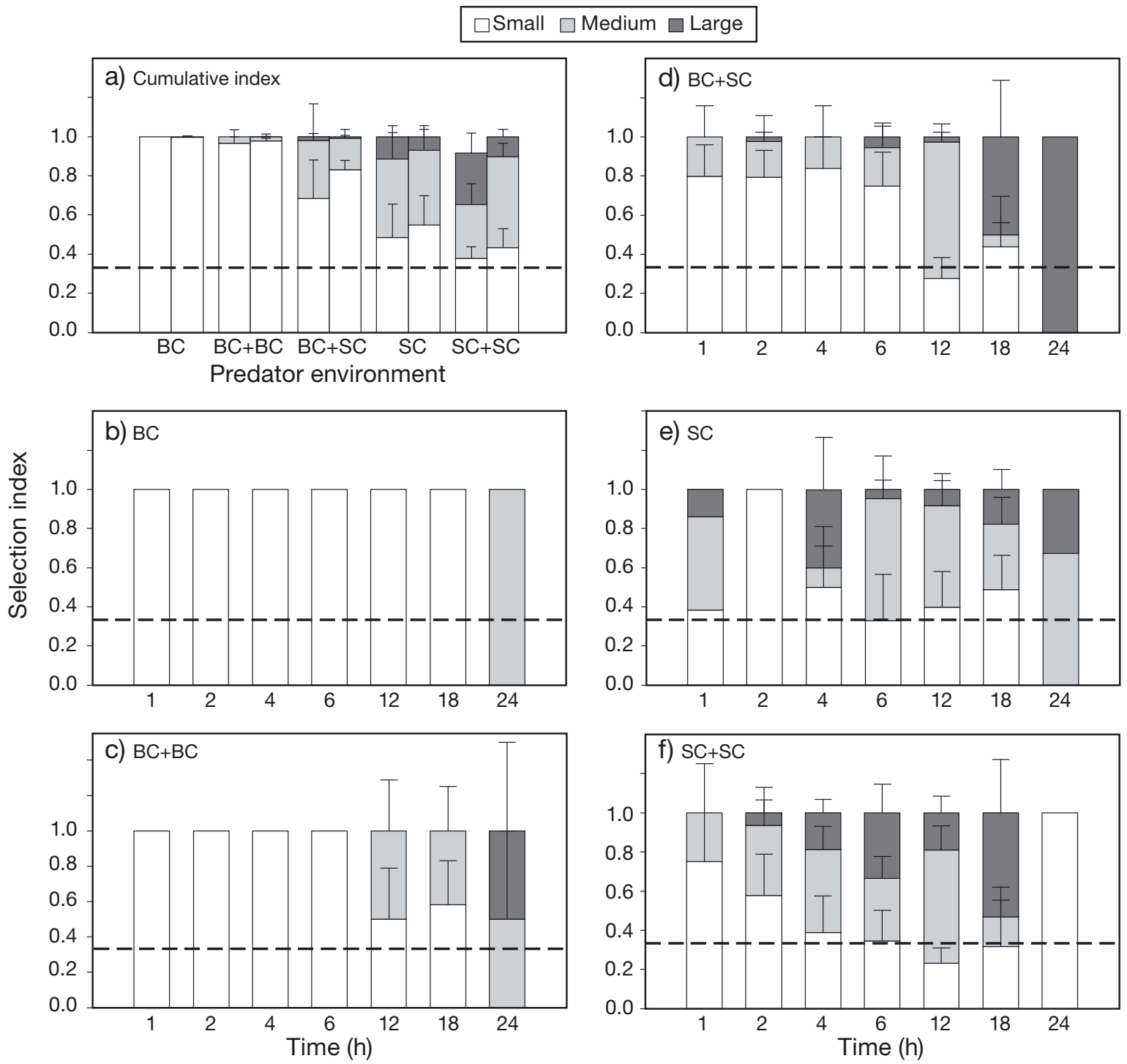

Fig. 3. Callinectes sapidus, Menippe mercenaria and Mercenaria mercenaria. Selection indices for small (10-30 mm SL), medium (31-40 mm SL) and large clam sizes (41-60 mm SL); (a) cumulative over time at the end of the multiple prey-size experiment and (b-f) calculated per time interval on hard bottom. In (a), the first bar of each predator environment is data from sand, and the second bar is data from hard bottom. In all panels, the dashed line represents no prey size selection by predators $(\alpha=0.333)$. BC: blue crab; $\mathrm{SC}$ : stone crab. Error bars are $+1 \mathrm{SE}, \mathrm{n}=3$ to 7

to be highest for single blue crabs on hard bottom compared to all other predator environments (Fig. 4a).

Encounter rate between predators in the multiple prey-size experiment was significantly higher on hard bottom than on sand (SNK test, $\mathrm{p}<0.05$; Table S2, Fig. 4b). Encounter rate between predators was significantly higher for the blue crab conspecific pairs than other predator environments across bottom type (SNK test, p < 0.05; Table S2, Fig. 4b). Encounters that ended in threatening behaviour were most evident between blue crab conspecifics than for other predator pairs. On sand, $\sim 50 \%$ of encounters between blue crab conspecifics ended in threatening behaviour, while $\sim 25 \%$ of encounters on hard bottom ended in threatening behaviour. Encounters between stone crab conspecifics ended mostly with non-aggression or fighting on both bottom types. On hard bottom, chasing between stone crab conspecifics was also observed. Encounters between blue crabs and stone crabs ended in threatening behaviour mostly when on sand. On hard bottom, $\sim 50 \%$ of encounters between interspecific crabs had non-aggressive outcomes. Blue crabs spent $\sim 29$ and $36 \%$ of their time watching the conspecific or stone $\mathrm{crab}$, respectively, when resting on hard bottom. On sand, this increased to $\sim 42$ and $48 \%$ of their time. Stone crabs did not show watching behaviour when in 

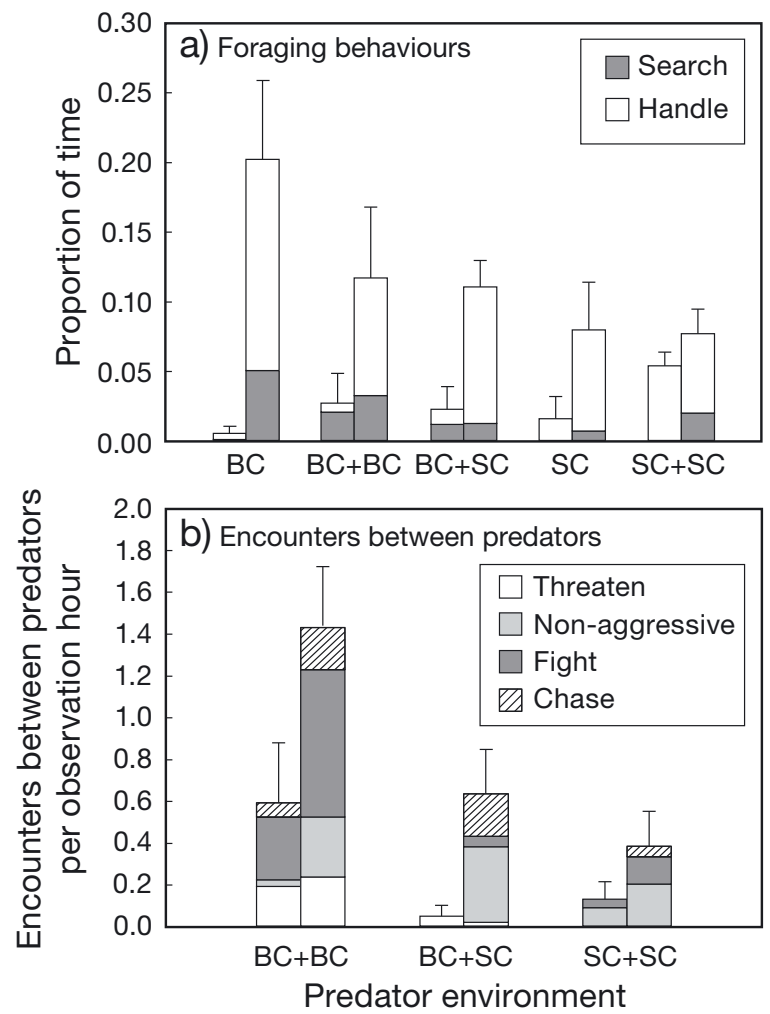

Fig. 4. Callinectes sapidus, Menippe mercenaria and Mercenaria mercenaria. (a) Foraging behaviours and (b) encounters between predators observed for blue crabs (BC) and stone crabs (SC) foraging on hard clams during the multiple preysize experiment. Data for $\mathrm{BC}+\mathrm{SC}$ are for observations of blue crabs. The first bar of each predator environment is data from sand, and the second bar is data from hard bottom. Error bars are $+1 \mathrm{SE}, \mathrm{n}=4$ to 7

interspecific pairs or conspecific pairs. When encounters between interspecifics ended in chasing, stone crabs chased blue crabs $100 \%$ of the time.

In the single prey-size experiment, encounter rate between blue crab conspecifics on sand was $8.8 \pm 2.8$ $($ mean $\pm \mathrm{SE}, \mathrm{n}=6)$. No encounters between stone crab conspecifics or between the interspecific crabs on sand were observed. On hard bottom, encounter rate between blue crab conspecifics was $12 \pm 9.2(\mathrm{n}=7)$ and between the interspecific crabs was $1.4 \pm 0.71(\mathrm{n}=8)$.

\section{DISCUSSION}

We found that both bottom type and prey size selection influenced multiple predator effects when blue crabs and stone crabs foraged on hard clams. On sand, all predator pairs had independent effects on prey, regardless of the presence or absence of multiple prey sizes. On hard bottom, in both experiments, some predator pairs had non-independent multiple predator effects on prey. The absence of multiple predator effects on sand resulted from certain predator behaviours induced by the sandy substrate. When on sand, both crab species spent a larger proportion of time resting ( $95 \%$ of time observed) compared to on hard bottom ( $\sim 75$ to $90 \%$ of time observed). Resting crabs either were buried in the sand, were inside or outside the shelters or watched the other predator when paired with a conspecific or interspecific crab. Thus, crabs spent less time foraging on sand than on hard bottom, resulting in few interactions between predators and, subsequently independent multiple predator effects on prey. In crab-bivalve systems, non-independent multiple predator effects on prey may be more common on hard bottom than on soft sediments. On hard bottom, prey may be easier to detect than on sand, because even slight bottom roughness can generate turbulence that impairs predator searching (Weissburg \& ZimmerFaust 1993). Easier detection of prey on hard bottom, combined with visual cues, would enhance foraging activity and interactions between predators. Although mid-Atlantic estuaries are mainly characterized by soft sediments, hard substrates are becoming increasingly prevalent with the construction of stone sills and bulkheads intended to reduce shoreline erosion (NRC 2007). These structures often support high densities of bivalves (M. Wong unpubl. data) that blue crabs and stone crabs can consume. Interactions between the crab species during foraging on epifauna may result in non-independent multiple predator effects on prey. However, effects may be mediated by prey characteristics not accounted for in our experiments, such as attachment of prey to the substrate through cementing (i.e. oysters) or byssal threads (i.e. mussels).

Prey size selection also influenced the effects of some predator pairs on hard clams. Risk reduction for prey resulted when blue crabs foraged together on an array of prey sizes on hard bottom. This non-independent multiple predator effect on prey was caused by aggressive interactions between blue crabs. Encounter rate between blue crab conspecifics was higher than that between stone crab conspecifics or the interspecific pair. Approximately $85 \%$ of encounters between blue crabs ended in aggressive interactions (i.e. threatening, fighting or chasing the other $\mathrm{crab}$ ). These reduced the proportion of time a blue crab spent foraging in the presence of a conspecific crab compared to isolated blue crabs. Aggressive interactions among blue crabs that result in mutual interference and lower foraging success often depend on prey distribution and density (Mansour \& Lipcius 1991, Clark et al. 1999a). In the present study, aggressive interactions between blue crabs likely resulted from prey size selection. Blue crabs strongly selected small clams (1020 and 21-30 mm SL) over large clams (31-60 mm SL), indicating that conspecifics of similar sizes were competing for the same sized prey. Competition for small prey 
was likely enhanced by the depletion of small clam abundance over time on hard bottom, causing blue crabs to compete for prey limited in availability. The aggressive interactions resulting from prey selection patterns reduced time spent foraging, and resulted in the observed non-independent multiple predator effect on prey when blue crab conspecifics foraged on hard bottom. Switching of blue crabs to larger prey $(31-40 \mathrm{~mm}$ SL) on hard bottom did not compensate for reduced availability of small clams, because larger clams required a significantly longer handling time than small clams. Blue crabs that differ in size often interact in nature (e.g. Clark et al. 1999b), and could also have multiple predator effects on prey.

On hard bottom during the multiple prey-size experiment, the interspecific pairs had a non-independent multiple predator effect that resulted in risk reduction for prey. The significant difference in magnitude between the predicted and observed proportions of biomass consumed for the interspecific pairs and the blue crab conspecific pairs indicated the effect was dependent on predator identity rather than predator density. Aggressive encounters and prey size selection did not cause the non-independent multiple predator effect on prey for the interspecific pairs as for blue crab conspecifics on hard bottom. Encounter rate between blue crabs and stone crabs on hard bottom was lower than between blue crab conspecifics, and the majority of encounters had non-aggressive outcomes. Most encounters between blue crabs and stone crabs may have had non-aggressive outcomes because the 2 species tend to forage at different times. Blue crab feeding activity reaches a maximum in the early to midmorning and in the evening (Clark et al. 1999b), while stone crabs are most active at dusk and night, with peak activity between 23:00 and 03:00 h (Brown \& Haight 1992). Non-aggressive encounters between blue crabs and stone crabs may have also occurred because stone crabs selected a larger range of prey sizes than blue crabs, reducing mutual interference for small clams. Despite relatively few aggressive encounters between blue crabs and stone crabs, the proportion of time spent foraging by blue crabs in the interspecific pair on hard bottom still tended to be lower than for isolated blue crabs. Time spent foraging by blue crabs was apparently reduced by behaviours such as watching, where blue crabs were inactive and watched the stone crabs. Watching behaviour was observed more often for interspecific than for conspecific predator pairs, and contributed to the observed multiple predator effect on prey.

Stone crab conspecifics foraged independently of each other on both bottom types in the multiple preysize experiment. Encounter rate between stone crabs was lower than that between the blue crabs in the con- specific pairs and crabs in the interspecific pairs. Some encounters between stone crab conspecifics ended in aggression (i.e. fighting and chasing), but these did not reduce the time a stone crab foraged in the presence of a conspecific compared to isolated stone crabs. Aggressive interactions between stone crab conspecifics are common, but are more apparent when individual CW differs by $>10 \mathrm{~mm}$ (Sinclair 1977, Brown \& Haight 1992). Aggressive interactions between stone crabs in our experiment were likely reduced because the crabs were similar in size in each replicate. Also, stone crabs consumed a wide range of clam sizes which indicates that competition between crabs for specific prey sizes (as observed for blue crab conspecifics on hard bottom) may have been limited.

In the single prey-size experiment, multiple predator effects on prey were absent when blue crab conspecific pairs and the interspecific pairs foraged on both bottom types. Comparison of results between the multiple and single prey-size experiments suggests that the interaction between the presence of multiple prey sizes and bottom type can influence the outcomes of interactions between multiple predators. In the single prey-size experiment on hard bottom, blue crab conspecifics and the interspecific pair reduced prey biomass by $\sim 30$ to $80 \%$ by the end of the trials, but overall predation remained independent and did not differ from predicted values. Although encounter rates between blue crab conspecifics and the interspecific crabs on hard bottom in the single prey-size experiment were slightly higher than those in the multiple prey-size experiment, mutual interference did not affect foraging success because the small prey preferred by blue crabs did not become as limited in abundance as they did in the multiple prey-size experiment. Facilitation of stone crab conspecifics was evident on hard bottom in the single prey-size experiment. Clark et al. (2000) found that facilitation among crabs can occur if chemical cues released from prey during crab consumption stimulate other crabs to forage.

The selection patterns of blue crabs that we documented are similar to those reported in other studies. We observed strong selection of small clams (10$30 \mathrm{~mm} \mathrm{SL}$ ) by blue crabs on both bottom types. Arnold (1984) found that when blue crabs (75-125 mm CW) were offered clams ranging in size from 5 to $25 \mathrm{~mm} \mathrm{SL}$, clams $10 \mathrm{~mm}$ in length were preferentially selected. In a similar experiment, Peterson (1990) found that blue crabs selected clams that were 5-15 mm SL. Micheli (1995) showed that larger blue crabs (124-158 mm $\mathrm{CW}$ ) preferred clams that were 15-25 mm SL. In the present study, blue crabs were offered a wider range of clam sizes (10-60 mm SL) than in previous studies. The majority of encounters between blue crabs and large clams (30-60 $\mathrm{mm} \mathrm{SL}$ ) ended in the clam being re- 
jected. However, blue crab conspecific pairs consumed some large clams when small clams (10-30 mm SL) were $\sim 70$ to $80 \%$ of their original abundance (note that one 30-40 $\mathrm{mm}$ SL clam was consumed by an isolated blue crab). Prey profitability (i.e. energy content divided by handling time per prey) for blue crabs increased with clam size. Ranking of prey profitability showed that blue crabs should include all clam sizes in their diet. This is contrary to results from the present study and others that show strong selection for small prey. However, preference for small, less profitable molluscan prey by crab predators has been well established (Juanes 1992, Smallegange et al. 2008). Crab predators incur non-lethal claw damage when handling large prey (Juanes 1992), which can reduce foraging efficiency and mating success, and increases vulnerability to aggressive interactions with other predators (Juanes \& Smith 1995).

On both bottom types, stone crabs consumed all sizes of clams offered and did not strongly select a certain prey size. Stone crab claws are morphologically stronger and have a higher mechanical advantage than blue crab claws (Schenk \& Wainwright 2001). Surprisingly, stone crabs consumed large clams (40$60 \mathrm{~mm}$ SL) less frequently than expected, and small and medium clams in proportion to their availability. This led to diet overlap with blue crabs because both species consumed small clams (10-30 mm SL). Although stone crabs consumed fewer large clams than expected, our results corresponded to predictions from ranking of prey profitability. Stone crabs can likely handle larger bivalves without incurring heavy claw damage. Aronhime \& Brown (2009) found results similar to ours in that Gulf stone crabs Menippe adina consumed all sizes of mussels Ischadium recurvum offered, but blue crabs selected small mussels. $M$. adina claws were less prone to damage than blue crab claws, and had the mechanical ability to handle large prey.

To our knowledge, the present study is one of the first to examine selection of prey within the context of multiple predators. Overall selection patterns were not altered by the presence of a conspecific for either predator species on both bottom types. While we were unable to directly quantify selection by individual crabs foraging with a conspecific or interspecific crab, the selection indices for small clams did not change between isolated and conspecific pairs of blue crabs or between isolated and conspecific pairs of stone crabs. This suggests that the presence of another predator (conspecific or interspecific) did not change selection behaviours of individual predators. Smallegange et al. (2008) monitored mussel Mytilus edulis prey size selection by individual shore crabs Carcinus maenas in the presence of a conspecific, and found that selection did not alter from when crabs foraged in isolation.

\section{CONCLUSIONS}

The expected increase in stone crab abundance in mid-Atlantic estuaries from a poleward range shift may result in interactions between stone crabs and other crab species that utilize similar resources. The multiple predator effects on prey will be influenced by the array of prey types available for consumption and bottom type. When foraging for hard clams in sand sediment, blue crabs and stone crabs will likely have independent multiple predator effects on hard clams because stone crabs will forage independently of blue crabs. In this case, overall consumption can be predicted from isolated crabs. However, this independent multiple predator effect may be influenced by factors not included in our experiments, such as prey patches, prey density or predator size. When foraging on hard structures, such as those constructed to reduce shoreline erosion, the 2 crab species may have non-independent effects and reduce predation risk of prey. The outcome of blue crab and stone crab foraging when on hard bottom will depend in part on the characteristics of epifaunal prey. Regardless of the presence or absence of multiple predator effects on prey, prey selection patterns of blue crabs and stone crabs will influence the dynamics of hard clam populations. Stone crabs readily consume small clams (10-30 mm SL) that are preferentially selected by blue crabs, which could shift size structure of hard clam populations if stone crabs increase in abundance. Additionally, stone crabs are efficient predators of large clams (30-60 mm SL), and in a climate-changed mid-Atlantic estuary, the size refuge large clams usually have from blue crab predation will be lost.

Acknowledgements. We thank J. Bissette, K. Frank, D. Gaskill, L. Jones, C. Maser and G. Medlin for technical support. M. Dowd provided modelling and statistical advice. Comments from C. Harms and reviewers greatly improved the manuscript. We gratefully acknowledge financial support from the National Oceanic and Atmospheric Administration's Center for Sponsored Coastal Ocean Research.

\section{LITERATURE CITED}

Arnold WS (1984) The effects of prey size, predator size, and sediment composition on the rate of predation of the blue crab, Callinectes sapidus Rathbun, on the hard clam, Mercenaria mercenaria. J Exp Mar Biol Ecol 80:207-219

Aronhime BR, Brown KM (2009) The roles of profit and claw strength in determining mussel size selection by crabs. J Exp Mar Biol Ecol 379:28-33

Brown KM, Haight ES (1992) The foraging ecology of the Gulf of Mexico stone crab Menippe adina (Williams et Felder). J Exp Mar Biol Ecol 160:67-80

Charnov EL (1976) Optimal foraging: attack strategy of a mantid. Am Nat 110:141-151

Chesson J (1983) The estimation and analysis of preference 
and its relationship to foraging models. Ecology 64: 1297-1304

Clark ME, Wolcott TG, Wolcott DL, Hines AH (1999a) Intraspecific interference among foraging blue crabs Callinectes sapidus: interactive effects of predator density and prey patch distribution. Mar Ecol Prog Ser 178:69-78

Clark ME, Wolcott TG, Wolcott DL, Hines AH (1999b) Foraging and agonistic activity co-occur in free-ranging blue crabs (Callinectes sapidus): observation of animals by ultrasonic telemetry. J Exp Mar Biol Ecol 233:143-160

Clark ME, Wolcott TG, Wolcott DL, Hines AH (2000) Foraging behavior of an estuarine predator, the blue crab Callinectes sapidus in a patchy environment. Ecography 23:21-31

> Griffen BD, Byers JE (2006) Partitioning mechanisms of predator interference in different habitats. Oecologia 146: $608-614$

Helmuth B, Mieszkowska N, Moore P, Hawkins SJ (2006) Living on the edge of two changing worlds: forecasting the responses of rocky intertidal ecosystems to climate change. Annu Rev Ecol Evol Syst 37:373-404

- Hibbert CJ (1977) Growth and survivorship in a tidal-flat population of the bivalve Mercenaria mercenaria from Southampton Water. Mar Biol 44:71-76

Hines AH, Haddon AM, Wiechert LA (1990) Guild structure and foraging impact of blue crabs and epibenthic fish in a subestuary of Chesapeake Bay. Mar Ecol Prog Ser 67: 105-126

Jachowski RL (1974) Agonistic behavior of the blue crab, Callinectus sapidus Rathbun. Behaviour 50:232-253

Johnson RA, Wichern DW (2002) Applied multivariate statistical analysis. Pearson Education, Upper Saddle River, NJ

> Juanes F (1992) Why do decapod crustaceans prefer smallsized molluscan prey? Mar Ecol Prog Ser 87:239-249

> Juanes F, Smith LD (1995) The ecological consequences of limb loss and damage in decapod crustaceans: a review and prospectus. J Exp Mar Biol Ecol 193:197-223

Lindberg WJ, Marshall MJ (1984) Species profiles: life histories and environmental requirements of coastal fishes and invertebrates (south Florida). Stone crab. US Fish Wildl Serv FWS/OBS-82/11.21. US Army Corps of Engineers, TR EL-82-4

Lipcius RN, Hines AH (1986) Variable functional responses of a marine predator in dissimilar homogeneous microhabitats. Ecology 67:1361-1371

Mansour RA, Lipcius RN (1991) Density-dependent foraging and mutual interference in blue crabs preying upon infaunal clams. Mar Ecol Prog Ser 72:239-246

> Micheli F (1995) Behavioural plasticity in prey-size selectivity of the blue crab Callinectes sapidus feeding on bivalve prey. J Anim Ecol 64:63-74

Murdoch WW (1969) Switching in general predators: experiments on predator specificity and stability of prey populations. Ecol Monogr 39:335-354

NRC (National Research Council) (2007) Mitigating shore erosion along sheltered coasts. National Academies Press, Washington, DC

Peterson CH (1990) On the role of ecological experimentation in resource management: managing fisheries through mechanistic understanding of predator feeding behaviour. In: Hughes RN (ed) Behavioural mechanisms of food selection. Springer-Verlag, New York, NY, p 821-846

Roa R (1992) Design and analysis of multiple-choice feedingpreference experiments. Oecologia 89:509-515

- Rovero F, Hughes RN, Chelazzi G (2000) When time is of the

Editorial responsibility: Paul Snelgrove,

St. John's, Newfoundland \& Labrador, Canada essence: choosing a currency for prey handling costs. J Anim Ecol 69:683-689

Sagarin RD, Gaines SD, Gaylord G (2006) Moving beyond assumptions to understand abundance distributions across the ranges of species. Trends Ecol Evol 21:524-530

Scheiner SM (2001) MANOVA: multiple response variables and multispecies interactions. In: Scheiner SM, Gurevitch $\mathrm{J}$ (eds) Design and analysis of ecological experiments. Oxford University Press, New York, NY, p 99-115

Schenk SC, Wainwright PC (2001) Dimophism and the functional basis of claw strength in six brachyuran crabs. J Zool 255:105-119

> Seitz RD, Lipcius RN, Hines AH, Eggleston DB (2001) Density-dependent predation, habitat variation, and the persistence of marine bivalve prey. Ecology 82:2435-2451

> Sih A, Englund G, Wooster D (1998) Emergent impacts of multiple predators on prey. Trends Ecol Evol 13:350-355

Sinclair ME (1977) Agonistic behaviour of the stone crab, Menippe mercenaria (Say). Anim Behav 25:193-207

> Smallegange IM, Hidding B, Eppenga JMA, van de Meer J (2008) Optimal foraging and risk of claw damage: How flexible are shore crabs in their prey size selectivity? J Exp Mar Biol Ecol 367:157-163

Soluk DA (1993) Multiple predator effects: predicting combined functional response of stream fish and invertebrate predators. Ecology 74:219-225

> Southward AJ, Hawkins SJ, Burrows MT (1995) Seventy years' observations of changes in distribution and abundance of zooplankton and intertidal organisms in the western English Channel in relation to rising sea temperature. J Therm Biol 20:127-155

> Sponaugle S, Lawton P (1990) Portunid crab predation on juvenile hard clams: effects of substrate type and prey density. Mar Ecol Prog Ser 67:43-53

Stephens DW, Krebs JR (1986) Foraging theory. Princeton University Press, Princeton, NJ

Vance-Chalcraft HD, Soluk DA (2004) Is prey predation risk influenced more by increasing predator density or predator species richness in stream enclosures? Oecologia 139:117-122

> Virnstein RW (1977) The importance of predation by crabs and fishes on benthic infauna in Chesapeake Bay. Ecology 58:1199-1217

Walther GR, Post E, Convery P, Menzel A and others (2002) Ecological responses to recent climate change. Nature 416:389-395

- Weissburg MJ, Zimmer-Faust RK (1993) Life and death in moving fluids: hydrodynamic effects on chemosensorymediated predation. Ecology 74:1428-1443

Wilbur HM, Fauth JE (1990) Experimental aquatic food webs: interactions between two predators and two prey. Am Nat 135:176-204

Williams AB (1965) Marine decapod crustaceans of the Carolinas. Fish Bull 65:1-208

- Wong MC, Barbeau MA (2005) Prey selection and the functional response of sea stars (Asterias vulgaris Verrill) and rock crabs (Cancer irroratus Say) preying on juvenile sea scallops (Placopecten magellanicus (Gmelin)) and blue mussels (Mytilus edulis Linnaeus). J Exp Mar Biol Ecol 327: $1-21$

Wong MC, Wright LD, Barbeau MA (2006) Sediment selection by juvenile sea scallops (Placopecten magellanicus (Gmelin)), sea stars (Asterias vulgaris Verrill) and rock crabs (Cancer irroratus Say). J Shellfish Res 25:813-821

Submitted: December 9, 2009; Accepted: April 13, 2010

Proofs received from author(s): June 6, 2010 